\title{
BoLA-DRB3 gene polymorphism and FMD resistance or susceptibility in Wanbei cattle
}

\author{
Wei Lei $\cdot$ Qinglong Liang $\cdot$ Luo Jing • \\ Chengmin Wang $\cdot$ Xiaobing $\mathrm{Wu} \cdot$ Hongxuan He
}

Received: 12 November 2011/ Accepted: 9 June 2012/Published online: 29 June 2012

(c) The Author(s) 2012. This article is published with open access at Springerlink.com

\begin{abstract}
For the further characterization of foot-andmouth disease virus (FMDV)-induced foot-and-mouth disease, we investigated the association between polymorphism of BoLA-DRB3 gene and FMD resistance/susceptibility of Wanbei cattle challenged with FMDV. One hundred cattle were challenged with FMDV and exon 2 of BoLA-DRB3 genes was amplified by hemi-nested polymerase chain reaction from asymptomatic animals and from animals with FMD. PCR products were characterized by the RFLP technique using restriction enzymes Hae III. The results revealed extensive polymorphisms, 6 RFLP patterns were identified. By analyzing alleles and genotypic frequencies between healthy and infection with FMD cattle, we found that allele Hae III A was associated with susceptibility to FMD in Wanbei cattle $(P<0.05)$, whereas Hae III C was associated with resistance to FMD $(P<0.01)$ and may have a strong protective effect against FMD. Hae IIICC and Hae III BC genotype were associated with resistance to FMD $(P<0.01)$. By contrast, Hae III
\end{abstract}

W. Lei · Q. Liang · L. Jing · C. Wang · H. He

Key Laboratory of Animal Ecology and Conservation Biology, Institute of Zoology, National Research Center For WildlifeBorne Diseases, Chinese Academy of Sciences, Beijing 100101, People's Republic of China

e-mail: hehx@ioz.ac.cn

W. Lei

Key Laboratory of Animal Genetics, Faculty of Animal Science, Suzhou Vocational and Technical College, Suzhou 234000,

Anhui, People's Republic of China

W. Lei $\cdot$ X. Wu $(\square)$

Anhui Provincial Key Laboratory of the Conservation and Exploitation of Biological Resources,

College of Life Sciences, Anhui Normal University,

Wuhu 241000, People's Republic of China

e-mail:wuxb@mail.ahnu.edu.cn
AA genotype was associated with susceptibility to FMD $(P<0.01)$. Sequence analysis show that 89 amino acids were translated in exon 2 of BoLA-DRB3 and $13.70 \%$ of nucleotide mutated, which resulted in $14.61 \%$ of amino acid change. One PKC, one Tyr and one CAMP phosphorylation were increased; the hydrophobicity and secondary structure of proteins produced change after amino acid substitution. These results revealed that Wanbei cattle had the ability of resistance to disease by mutation which result changes of the protein structure to perform the regulation of the cell using different signaling pathways in the long process of choice evolution.

Keywords BoLA-DRB3 - Polymorphism - FMD · Resistance $\cdot$ Susceptibility

\section{Introduction}

The foot-and-mouth disease virus (FMDV) was a member of the genus Aphthovirus in the family Picornaviridae. There were seven immunologically distinct serotypes-O, A, C, SAT 1, SAT 2, SAT 3 and Asia 1-and over 60 strains within these serotypes. FMDV serotypes and strains vary within each geographic region. Serotype $O$ was the most common serotype worldwide. FMDV can infect most or all members of the order Artiodactyla (cloven-hooved mammals), as well as a few species in other orders. On most continents, cattle were usually the most important maintenance hosts for FMDV. Although this epizootic can be controlled by the use of a chemically inactivated whole virus vaccine, many countries have abandoned vaccination due to several disadvantages of this vaccine [1].

Evolutionary biology was increasingly concerned with the study of infectious diseases [2-4], for example host 
heterogeneity in disease susceptibility, which was thought to play a major role in disease persistence [5-7]. Immunogenetic studies and molecular advances provide powerful tools for understanding protective and pathogenic mechanisms in such infectious disease and make possible the study of the genetic basis of host resistance [8-11]. Specifically, in the case of disease infection, genes located in different regions of the host genome have been implicated in resistance to infection. Immunogenetics has mainly focused on major histocompatibility complex (MHC). MHC was genetic region consisting of a group of closely linked and highly polymorphic loci on chromosome, which played a central role in the immune response and immunological recognition. MHC was unique in their general importance for conferring susceptibility or resistance to infectious and autoimmune diseases [12-14].

Many studies showed that polymorphism in the genes for BoLA class II molecules determines the specificity of the immune response and plays a role in conferring resistance or susceptibility to: (a) chronic autoimmune disorders such as rheumatoid arthritis, insulin-dependent diabetes mellitus, pemphigus vulgaris, and multiple sclerosis [15]; (b) infectious diseases such as tuberculoid leprosy and malaria $[16,17]$; and (c) malignancies such as carcinoma and melanoma [18-21]. Among BoLA class II genes, BoLA-DRB3 functional genes, which were highly polymorphic, were found to have a stronger association with resistance/susceptibility to bovine leukemia virus [22], dermatophilosis and mastitis [23] than DRB2 or DQB. The range of MHC class II BoLA-DRB3 gene polymorphisms associated with resistance and susceptibility to some infection disease in cattle was confirmed [22, 24].

Up to now, study for BoLA-DRB3 gene polymorphisms associated with resistance or susceptibility to FMD has not been reported in cattle. There was a lack of comparative data from resistant and susceptible cattle to clarify differences in immunological processes, notably molecular levels. We thus decided to investigate BoLA-DRB3 as a candidate gene for FMD resistance in Wanbei cattle. The objective of this preliminary study was to describe the genetic variability and allele frequency in the exon 2 of BoLA-DRB3 genes using PCR-RFLP method and to investigate BoLA-DRB3 alleles association with resistance and susceptibility to FMD in Wanbei cattle, to set a direction for the future studies.

\section{Materials and methods}

Cattle sampling and experimental FMDV challenge

Wanbei cattle of 1-2 years of age were collected from Anhui, Jiangsu and Henan province in China. In order to contrast FMD-susceptible and FMD-resistant individuals, cattle were experimentally challenged with FMDV. First, the FMD serology status of each animal was established using FMDV-specific antibodies assay, and only seronegative individuals were included in these experiments. 100 cattle sampling were brought to the experimental area isolated for experimental challenge (at least 3 weeks of quarantine). Subsequently, cattle were inoculated with $5.0 \mathrm{ml}$ of blood from FMDV infected cattle. Inoculated cattle were monitored for 3 weeks. Then we classified the cattle into two types: (a) FMDV infected but clinically normal cattle; and (b) cattle with FMD. Two approaches were carried out. First, we used animals experimentally challenged with FMDV, and we compared the BoLADRB3 genotypes of susceptible (cattle with FMD) and resistant (FMDV infected but clinically normal cattle. Second, we compared BoLA-DRB3 allelic frequencies in cattle infected by FMDV but clinically normal and cattle with FMD.

\section{DNA extraction and amplification of BoLA-DRB3}

100 blood samples of Wanbei cattle, which included 68 healthy and 32 infected with FMD. Genomic DNA was extracted from whole blood $(100 \mu \mathrm{l})$ by the phenol-chloroform extraction method described by Sambrook with some modifications. The concentration and purity of obtained DNA were assessed by spectrophotometery and electrophoresis in $1 \%$ agarose gels, respectively. Exon 2 of BoLA-DRB3 gene was amplified by hemi-nested PCR, described by Miretti, to improve the specificity of the PCR product. Primers (FHL010: 5'-ATCCTCTCTCTGCAGCACATTTCC-3'; RHL011: 5'-CTTGAATTCGCGCTCACCTCGCCGCTG-3'; RHL012: 5'-TCGCCGCTGCAC AGTGAAACTCTC- $3^{\prime}$ ), described by Van Eijk, were used in the PCR reaction. Briefly, the first stage PCR was performed in a final volume of $20 \mu \mathrm{l}$ containing $50 \mathrm{ng}$ of template DNA, $0.5 \mathrm{pm}$ of primer FHL010 and RHL011, $2 \mu \mathrm{l}$ PCR buffer, $1.75 \mathrm{mM} \mathrm{MgCl}_{2}, 0.25 \mathrm{mM}$ dNTPs, $1.5 \mathrm{U}$ Taq DNA Polymerase (Shanghai Sangon). This reaction system was predenatured at $94{ }^{\circ} \mathrm{C}$ for 4 min followed by 12 cycles of denaturizing $\left(94^{\circ} \mathrm{C}\right.$ for $\left.1 \mathrm{~min}\right)$, annealing $\left(60{ }^{\circ} \mathrm{C}\right.$ for $\left.1 \mathrm{~min}\right)$ and elongation $\left(72{ }^{\circ} \mathrm{C}\right.$ for $\left.1 \mathrm{~min}\right)$ and a final extension at $72{ }^{\circ} \mathrm{C}$ for $5 \mathrm{~min} .2 \mu \mathrm{l}$ of the first stage PCR product was used as template DNA. For the second stage PCR in a final volume of $40 \mu$ containing $0.5 \mathrm{pM}$ of primer FHL010 and RHL-012, $4 \mu \mathrm{l}$ PCR buffer $1.75 \mathrm{mM}$ $\mathrm{MgCl}_{2}, 0.25 \mathrm{mM}$ dNTPs and $2 \mathrm{U}$ Taq DNA polymerase. The solution was predenatured at $94{ }^{\circ} \mathrm{C}$ for 4 min followed by 30 cycles of denaturizing $\left(94^{\circ} \mathrm{C}\right.$ for $\left.60 \mathrm{~s}\right)$, annealing $\left(63{ }^{\circ} \mathrm{C}\right.$ for $\left.45 \mathrm{~s}\right)$, and elongation $\left(72{ }^{\circ} \mathrm{C}\right.$ for $45 \mathrm{~s}$ ) and a final extension $\left(72{ }^{\circ} \mathrm{C}\right.$ for $5 \mathrm{~min}$ ). Then, $5 \mu \mathrm{l}$ of PCR products were subjected to electrophoresis in a $2 \%$ agarose gel in 
order to check the quality and specificity of amplified DNA fragment.

Restriction fragment length polymorphism (RFLP) analysis

Discrimination of polymorphism in BoLA class II DRB3 gene in this paper was performed by RFLP of the amplified fragments utilizing restriction sites unique for HaeIII. Twenty microliter of PCR product that contained a fragment of the expected size was then digested with 10 Units of each restriction enzyme used in this study in final reaction on volume $25 \mu \mathrm{l}$. The reaction mixture was incubated at $37{ }^{\circ} \mathrm{C}$ for HaeIII in water bath over night. Restriction fragments were revealed by gel electrophoresis on $12 \%$ PAGE under $150 \mathrm{~V}$ for $5 \mathrm{~h}$, using Msp I digested pBR322/MspIas a molecular marker.

\section{Statistic analyses}

The allele frequency $(\mathrm{P})$ and genotypic frequency $(\mathrm{G})$ were calculated based on Wang [25]. Two approaches were carried out. First, we compared the BoLA-DRB3 genotypes of susceptible (infection) and resistant (healthy) cattle. Second, we described the genetic variability and compared BoLA-DRB3 allelic frequencies between healthy and infection with FMD cattle. The statistical significance of differences between genotype and resistance/susceptibility to FMD were analyzed using SPSS 18.0 software, the difference is considered statistically significant when $P$ was 0.05 .

\section{Results}

PCR products

PCR products were detected by $2 \%$ agarose gel electrophoresis, the results showed that the amplified products

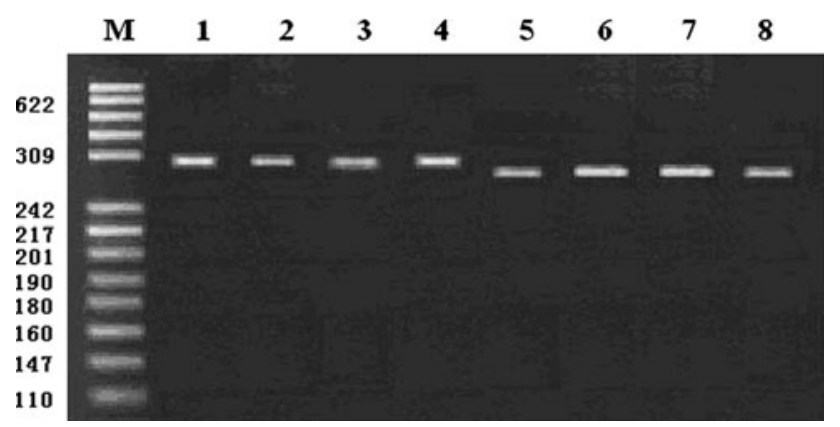

Fig. 1 PCR products are examined by $2 \%$ agarose gel electrophoresis

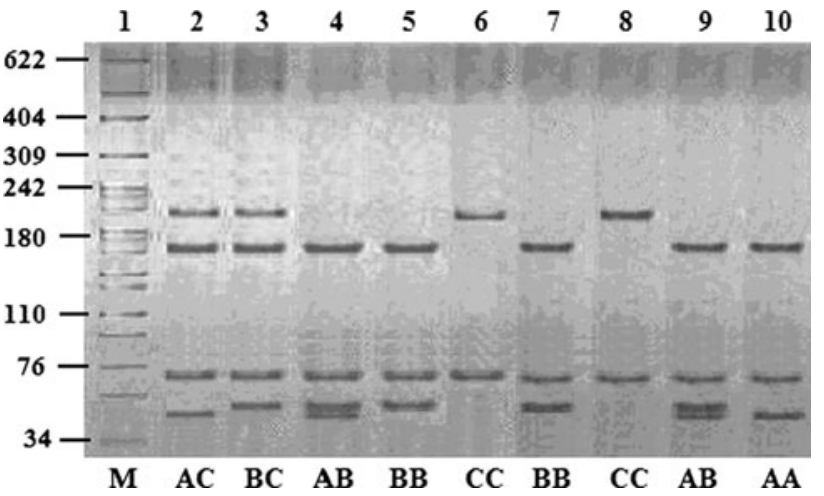

Fig. 2 Bind patterns of DRB3 locus digested with Hae III

were 302 and 284 bp in length with good specificity, which consistent with the expected fragment (Fig. 1).

Identification of restriction patterns

The $284 \mathrm{bp}$ fragment of the BoLA-DRB3.2 gene in this study were digested with Hae III. 6 RFLP patterns were identified (167/65/48/4, 167/65/52, 219/65, 167/65/52/48/ 4, 219/65/48/4, 219/65/52 bp) and named AA, BB, CC, $\mathrm{AB}, \mathrm{AC}$ and BC. 3 allele were found in Wanbei cattle and named $\mathrm{A}, \mathrm{B}$ and $\mathrm{C}$. The results were showed in Fig. 2.

Analysis of DNA sequences

Cloning and sequencing results showed that $284 \mathrm{bp}$ fragments were amplified, including 15 bp intron 1 and 269 bp exon 2. 38 bases mutations were found by aligning the sequence of homozygous and GenBank (gi:21668455) (Fig. 3), and mutations produced HaeIII polymorphism at 154, 155, 156 and 157 position (Table 1). 89 amino acids were translated in exon 2 of BoLA-DRB3 (http://www. ncbi.nlm.nih.gov/BLAST/Blast.cgi). Among these amino acid sequences, there were 13 substitutions by comparing with the GenBank sequence (NP-001012698). One PKC, one Tyr and one CAMP phosphorylation were increased after amino acid substitution (http://www.expasy.org/ prosite/). However, one $\alpha$-helix structure was reduced in the secondary structure of protein (http://npsa-pbil.ibcp.fr/ ); protein hydrophobic was significantly lower from 40 to 50 (http://www.expasy.org/tools/protscale.html).

The frequency of BoLA-DRB3 alleles in infected FMD and healthy cattle

There were the same alleles and genotype in healthy and infection with FMD cattle. The numbers and frequency of the BoLA-DRB3 alleles in infected FMD and healthy Wanbei cattle were shown in Table 2. The frequency of HaeIIIA, HaeIIIB and HaeIIIC were 0.2059, 0.3309 and 
Exton 2

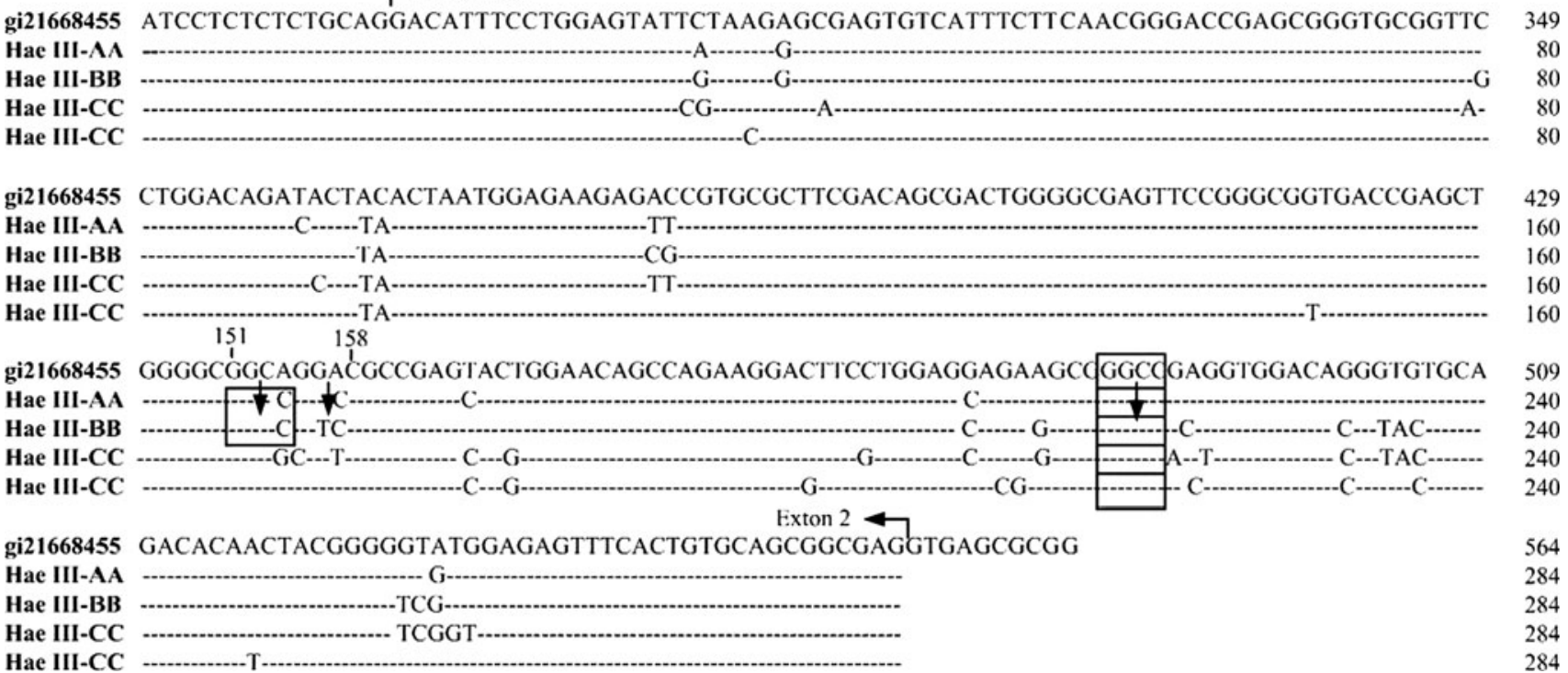

Fig. 3 The blast of sequence of DRB3 with different genotype

0.4632 in healthy cattle respectively. The frequency of HaeIIIA, HaeIIIB and HaeIIIC were 0.4844, 0.1875 and 0.0469 in FMD cattle, respectively. The frequency of HaeIIIAA, HaeIIIBB, HaeIIICC, HaeIIIAB, HaeIIIAC and HaeIIIBC were $0.0882,0.1324,0.2648,0.1176,0.1176$ and 0.2794 in healthy cattle, respectively; the frequency of HaeIIIAA, HaeIIIBB, HaeIIICC, HaeIIIAB, HaeIIIAC and HaeIIIBC were $0.2344,0.1875,0.0625,0.1563,0.1250$ and 0.0625 in FMD cattle, respectively.

\section{Discussion}

The BoLA-DRB3 polymorphism in Wanbei cattle

Statistical results showed that 38 bases mutations were found and polymorphism sites at positions 154, 155, 156 and 157 in Wanbei cattle. Sequence analysis showed that 89 amino acids were translated in exon 2 of BoLA-DRB3 and $13.70 \%$ of nucleotide mutated, which resulted in $14.61 \%$ of amino acid change. One PKC, one Tyr and one
Table 2 Allele frequencies of BoLA-DRB3 for FMDV-challenged cattle

\begin{tabular}{clllll}
\hline & $\begin{array}{l}\text { Health } \\
(n=68)\end{array}$ & Frequency & Allele & $\begin{array}{l}\text { FMD } \\
(n=32)\end{array}$ & Frequency \\
Allele & No & 0.2059 & $\begin{array}{c}\text { HaeIII } \\
\text { A }\end{array}$ & 35 & $0.4844^{*}$ \\
\hline $\begin{array}{c}\text { HaeIII } \\
\text { A }\end{array}$ & 28 & 0.3309 & $\begin{array}{c}\text { HaeIII } \\
\text { B }\end{array}$ & 19 & 0.1875 \\
$\begin{array}{c}\text { HaeIII } \\
\text { B }\end{array}$ & 45 & $0.4632 * *$ & $\begin{array}{c}\text { HaeIII } \\
\text { C }\end{array}$ & 3 & 0.0469 \\
$\begin{array}{c}\text { HaeIII } \\
\text { C }\end{array}$ & 63 & \multicolumn{3}{c}{\begin{tabular}{c} 
\\
\hline
\end{tabular}}
\end{tabular}

Note The same alleles between positive and negative FMD

$* P<0.05, * * P<0.01$

CAMP phosphorylation were increased and the hydrophobicity and secondary structure of proteins produced changes after amino acid substitution. The results in this study were consistent with findings obtained by Wang [25]. These results revealed that cattle had the ability of

Table 1 Variant position and sequence of three RFLPs-HaeIII of exon 2

\begin{tabular}{llllll}
\hline Genotypes & Partial sequence $\left(5^{\prime} \rightarrow 3^{\prime}\right)$ & Variant position & Variant sequence & Number of digestion point & Fragment size (bp) \\
\hline AA & 151-GGCCGGCC-158 & & & 3 & $167,65,48,4$ \\
BB & 151-GGCCGTCC-158 & 156 & $\mathrm{G} \rightarrow \mathrm{T}$ & 2 & $167,65,52$, \\
CC & 151-GGCGCGTC-158 & 154 & $\mathrm{C} \rightarrow \mathrm{G}$ & 1 & 219,65 \\
& & 155 & $\mathrm{G} \rightarrow \mathrm{C}$ & & \\
& & 157 & $\mathrm{C} \rightarrow \mathrm{T}$ & & \\
& 151-GGCAGGAC-158 & 154 & $\mathrm{C} \rightarrow \mathrm{A}$ & $\mathrm{C} \rightarrow \mathrm{A}$ & \\
\hline
\end{tabular}


resistance to disease by mutation which result changes of the protein structure to perform the regulation of the cell using different signaling pathways in the long process of choice evolution [25].

BoLA-DRB3 alleles associated with resistance and susceptibility to FMD

There were the same alleles and genotype in healthy and infection with FMD cattle. The numbers and frequency of the different BoLA-DRB3 alleles in infected FMD and healthy Wanbei cattle were shown in Table 2. HaeIII C allele was present at a significantly higher frequency in healthy cattle as compared with cattle with FMD (healthy 0.4632; FMD 0.0469). The frequency of cattle infected FMD for HaeIII A (0.4844) was higher than healthy cattle for the same allele (0.2059). No other alleles were associated with a statistically significant difference between healthy and infection with FMD cattle. This result suggested that allele HaeIII A was associated with susceptibility to FMD in Wanbei cattle $(P<0.05)$, whereas HaeIII $\mathrm{C}$ was associated with resistance to FMD $(P<0.01)$ and may have a strong protective effect against FMD.

We compared frequencies of BoLA-DRB3 genotypes in healthy and infection with FMD cattle (Table 3 ). The frequency of HaeIII CC and HaeIII BC was higher in healthy cattle than in FMD cattle for the same genotypes (healthy $0.2648,0.2794$; FMD 0.0625, 0.0625). This result suggested that HaeIII CC and HaeIII BC genotype were actually associated with resistance to FMD $(P<0.01)$. By contrast, HaeIII AA genotype was associated with susceptibility to FMD $(P<0.05)$. In the case of Hae III BB, Hae III AB and HaeIII AC genotypes, the differences between healthy and FMD cattle were not significant.

Table 3 Genotypic frequencies of BoLA-DRB3 for FMDV-challenged cattle

\begin{tabular}{|c|c|c|c|c|c|}
\hline Genotype & $\begin{array}{l}\text { Health } \\
(n=68) \\
\text { No }\end{array}$ & Frequency & Genotype & $\begin{array}{l}\text { FMD } \\
(n=32) \\
\text { No }\end{array}$ & Frequency \\
\hline $\begin{array}{c}\text { BstYI } \\
\text { AA }\end{array}$ & 6 & 0.0882 & $\begin{array}{c}\text { BstYI } \\
\text { AA }\end{array}$ & 15 & $0.2344 * *$ \\
\hline $\begin{array}{c}\text { BstYI } \\
\text { BB }\end{array}$ & 9 & 0.1324 & $\begin{array}{c}\text { BstYI } \\
\text { BB }\end{array}$ & 6 & 0.1875 \\
\hline $\begin{array}{c}\text { HaeIII } \\
\text { CC }\end{array}$ & 18 & $0.2648 * *$ & $\begin{array}{c}\text { HaeIII } \\
\text { AA }\end{array}$ & 2 & 0.0625 \\
\hline $\begin{array}{c}\text { HaeIII } \\
\text { AB }\end{array}$ & 8 & 0.1176 & $\begin{array}{c}\text { HaeIII } \\
\text { AB }\end{array}$ & 5 & 0.1563 \\
\hline $\begin{array}{c}\text { HaeIII } \\
\text { AC }\end{array}$ & 8 & 0.1176 & $\begin{array}{c}\text { HaeIII } \\
\text { BB }\end{array}$ & 4 & 0.1250 \\
\hline $\begin{array}{c}\text { HaeIII } \\
\text { BC }\end{array}$ & 19 & $0.2794 * *$ & $\begin{array}{c}\text { HaeIII } \\
\text { AD }\end{array}$ & 2 & 0.0625 \\
\hline
\end{tabular}

Note The genotypes between positive and negative FMD

$* P<0.05, * * \quad P<0.01$
BoLA-DRB3 played a key role in immune response to foot-and-mouth disease [26]. Baxtera et al. [27] studied the associations between bovine MHC DRB3 alleles and their binding pockets with the immune response to a 40-mer peptide derived from FMDV VP1. Eighteen different DRB3 alleles were detected in a crossbred (Charolais and Holstein) cattle population, with several exhibiting highly significant associations with antibody response. Allele DRB3*1601 was correlated with relatively low IgG1 and IgG2 responses $(P<0.001)$, whereas DRB3*1001 was associated with relatively high $\mathrm{IgG} 1$ and $\mathrm{IgG} 2$ responses $(P<0.001)$. The data indicated that the DRB3 alleles were critical for determining the degree of immune response. In this paper, Hemi-nested PCR-RFLP method was used for identification the frequency of $B o L A-D R B 3$ alleles and genotypes in Wanbei cattle. 6 RFLP patterns were found with enzymes Hae III. Based on analysis of significant difference of allele and genotypic frequencies in infected FMD and healthy cattle, our results demonstrated the existence of alleles associated with resistance and susceptibility to FMD. The allele Hae III A was associated with susceptibility in Wanbei cattle $(P<0.05)$; But the allele Hae III C was associated with resistance $(P<0.01)$; the genotypes of Hae IIICC and HaeIIIBC were associated with resistance to FMD $(P<0.01)$. By contrast, Hae IIIAA genotype was associated with susceptibility to FMD $(P<0.05)$.

The highly polymorphic bovine MHC (BoLA)-DRB gene had been implicated in the resistance and susceptibility to a broad range of diseases [13]. Earlier studies showed that some bovine MHC class II BoLA-DRB3.2 gene polymorphic were correlated with resistance and susceptibility to the development of persistent lymphocytosis (PL) cased by bovine leukaemia virus (BLV) infection [22, 28]. Subsequently, Panei et al. [29] identified 17 BoLA-DRB3 alleles defined according to the PCR-RFLP nomenclature and represented the distribution of the allele frequent in HolandoArgentino dairy cattle. Alleles BoLA-DRB3.2*11, *23 and $* 28$ mediating resistance to PL and alleles BoLA-DRB3.2*22 and $* 24$ mediating susceptibility to PL were observed, alleles BoLA-DRB3.2*25 and *40 also showed signification association to PL. The DRB3 polymorphism has also been observed to be associated with resistance or susceptibility to dermatophilosis, cystic ovarian and mastitis [30-33].

MHC molecules were important in disease resistance for many infectious agents. This study was the first to investigate the association between BoLA-DRB3 polymorphism and FMD among Wanbei cattle natural population and demonstration that $\mathrm{MHC}$ can have a role in the clearance of FMDV infections. This study suggested that MHC-mediated immune recognition can be an important variable in susceptibility to FMDV infections. However, the limitation of this preliminary study was that the sample size was not 
relatively large $(n=100)$ and these finding may not apply to all Wanbei cattle. Additional studies were required to define in detail the mechanism of the association between susceptibility to FMD and polymorphism of MHC class II alleles. Therefore, alterations in the biochemical nature and physiological function of BoLA-DRB3 molecules in association with resistance or susceptibility to FMD were also worthy of further examination.

Acknowledgments This study was supported by Grants for Science and Technology research of Suzhou (2009021) and the National Key Basic Research and Development Program of China (973200 7BC109103).

Open Access This article is distributed under the terms of the Creative Commons Attribution License which permits any use, distribution, and reproduction in any medium, provided the original author(s) and the source are credited.

\section{References}

1. Mahy BWJ (2004) Overview of foot-and mouth disease and its impact as a re-emergent viral infection. In: Sobrino F, Domingo E (eds) Foot and mouth disease. Current perspectives. Horizon Bioscience, Norfolk, pp 437-446

2. Levin BR, Lipsitch M, Bonhoeffer S (1999) Population biology, evolution, and infectious disease: convergence and synthesis. Science 283:806-809

3. Quintana-Murci L, Alcais A, Abel L, Casanova JL (2007) Immunology in natura: clinical, epidemiological and evolutionary genetics of infectious diseases. Nat Immunol 8:1165-1171

4. Nesse RM, Stearns SC (2008) The great opportunity: evolutionary applications to medicine and public health. Evol Appl 1:28-48

5. Anderson R, May R (1991) Infectious diseases in humans. Oxford University Press, Oxford

6. Dwyer G, Elkinton JS, Buonaccorsi JP (1997) Host heterogeneity in susceptibility and disease dynamics: tests of a mathematical model. Am Nat 150:685-707

7. Woolhouse MEJ, Dye C, Etard JF, Smith T, Charlwood JD, Garnett GP, Hagan P, Hii JLK, Ndhlovu PD, Quinell RJ, Watts $\mathrm{CH}$, Chandiwana SK, Anderson R (1997) Heterogeneities in the transmission of infectious agents: implications for the design of control programs. Proc Nat Acad Sci USA 94:338-342

8. McLeod R, Buschman E, Arbuckle LD, Skamene E (1995) Immunogenetics in the analysis of resistance to intracellular pathogens. Curr Opin Immunol 7:539-552

9. McLeod R, Johnson J, Estes R, Mack D (1996) Immunogenetics in pathogenesis of and protection against toxoplasmosis. Curr Top Microbiol Immunol 219:95-112

10. Mack DG, Johnson JJ, Roberts F, Roberts CW, Estes RG, David C, Grumet FC, Mcleod R (1999) HLA-class II genes modify outcome of Toxoplasma gondii infection. Int J Parasitol 29:1351-1358

11. Cooke GS, Hill AVS (2001) Genetics of susceptibility to human infectious disease. Nat Rev Genet 2:967-977

12. Baum H, Staines NA (1997) MHC-derived peptides and the CD4 T-cell repertoire: implications for autoimmune disease. Cytokines Cell Mol Ther 3:115-125

13. Rupp R, Hemandez A, Mallard BA (2007) Association of bovine leukocyte antigen (BoLA) DRB3.2 with immune response, mastitis and production and type traits in Canadian Holsteins. J Dairy Res 90:1029-1038

14. Hidaka M, Inoue J, Yoshida M, Seiki M (1988) Post-transcriptional regulator (rex) of HTLV-1 initiates expression of viral structural proteins but suppresses expression of regulatory proteins. J EMBO 7:519-523

15. Todd JA, Acha-Orbea H, Bell JI, Chao N, Fronek Z, Jacob CO, McDermott M, Sinha AA, Timmerman L, Steinman L, McDevitt HO (1988) A molecular basis for MHC class II-associated autoimmunity. Science 240:1003-1009

16. Zerva L, Cizman B, Mehra NK, Alahari SK, Murali R, Zmijewski CM, Kamoun M, Monos DS (1996) Arginine at positions 13 or $70-71$ in pocket 4 of HLA-DRB1 alleles is associated with susceptibility to tuberculoid leprosy. J Exp Med 183:829-836

17. Hill AV, Allsopp CE, Kwiatkowski D, Anstey NM, Twumasi P, Rowe PA, Bennett S, Brewster D, McMichael AJ, Greenwood BM (1991) Common West African HLA antigens are associated with protection from severe malaria. Nature (Lond) 352:595-600

18. Özdemir E, Kakehi Y, Nakamura E, Kinoshita H, Terachi T, Okada Y, Yoshida O (1997) HLA-DRB1*0101 and *0405 as protective alleles in Japanese patients with renal cell carcinoma. Cancer Res 57:742-746

19. Wank R, Thomssen C (1991) High risk of squamous cell carcinoma of the cervix for women with HLA-DQw3. Nature 352:723-725

20. Glew SS, Stern PL, Davidson JA, Dyer PA (1992) HLA antigens and cervical carcinoma. Nature 56:22

21. Lee JE, Reveille JD, Ross MI, Platsoucas CD (1994) HLADQB ${ }^{*} 0301$ association with increased cutaneous melanoma risk. Int J Cancer 59:510-513

22. Xu A, van Eijk MJ, Park C, Lewin HA (1993) Polymorphism in BoLA-DRB3 exon 2 correlates with resistance to persistent lymphocytosis caused by bovine leukemia virus. J Immunol 151:6977-6985

23. Maillard JC, Martinez D, Bensaid A (1996) An amino acid sequence coded by the exon 2 of the BoLA DRB3 gene associated with a BoLA class I specificity constitutes a likely genetic marker of resistance to dermatophilosis in Brahman zebu cattle of Martinique (FWI). Ann NY Acad Sci 791:185-197

24. Lewin HA, Russell GC, Glass EJ (1999) Comparative organization and function of the major histocompatibility complex of domesticated cattle. Immunol Rev 167:145-158

25. Wang XP, Xu SZ, Zan LS, Chen JB, Gao X, Ren HY (2007) Polymorphism and sequence analysis of the exon 2 of BoLADRB3 in cattle. J Agric Biotechnol 15(1):46-51

26. Ledwidge SA, Mallard BA, Gibson JP, Jansen GB, Jiang ZH (2001) Multi-primer target PCR for rapid identification of bovine DEB3 alleles. Anim Genet 32:219-221

27. Baxtera R, Craigmile SC, Haleya C, Douglasc AJ, Williamsd JL, Class EJ (2009) BoLA-DR peptide binding pockets are fundamental for foot-and-mouth disease virus vaccine design in cattle. Vaccine 28(1):28-37

28. Zanotti M, Poli G, Ponti W, Polli M, Rocchi M, Bolzani E, Longeri M, Russo S, Lewin HA, van Eijk MJT (1996) Association of BoLA class I haplotypes with subclinical progression of bovine leukemia virus infection in Holstein-Friesian cattle. Anim Genet 27:337-341

29. Panei CP, Suzuki K, Echeverria MG, Serena MS, Metz GE, Gonzàlez ET (2009) Association of BoLA-DRB3 alleles with resistance and susceptibility to persistent lymphocytosis in BLV infected cattle in Argentina. Int J Dairy Sci 4(3):123-128

30. Maillard JC, Renard C, Cardom P, Chantal I, Bensaid A (1999) Characterization of 18 new BoLA-DRB3 alleles. Anim Genet 30:200-203

31. Maillard JC, Chantal I, Berthier D (2001) Sequencing of four new BoLA-DRB3 and six BoLA-DRB alleles. Anim Genet 32:40-53 
32. Bjorkman PJ, Saper MA, Samraoui B, Bennett WS, Strominger JL, Wiley DC (1987) Structure of the human class I histocompatibility antigen, HLA-A2. Nature 329:506-512
33. Nassiry MR, Shahroodi FE, Mosafer J, Mohammadi A, Manshad E, Ghazanfari S, Mohammad Abadi MR, Sulimova GE (2005) Analysis and frequency of bovine lymphocyte antigen (BoLADRB3) alleles in Iranian Holstein cattle. Genetika 41(6):817-822 